\title{
Protonation and Solvation Thermodynamics of Some Naphthol Derivatives in KCl Aqueous Solution of Different Ionic Strengths
}

\author{
Farid I. El-Dossoki \\ Chemistry Department, Faculty of Science, Port Said University, Port Said 42521, Egypt \\ Correspondence should be addressed to Farid I. El-Dossoki; feldossoki64@yahoo.com
}

Received 2 November 2015; Revised 5 December 2015; Accepted 8 December 2015

Academic Editor: Giuseppe Gattuso

Copyright ( 2016 Farid I. El-Dossoki. This is an open access article distributed under the Creative Commons Attribution License, which permits unrestricted use, distribution, and reproduction in any medium, provided the original work is properly cited.

\begin{abstract}
The acid-base properties of naphthalen-1-ol (L1), naphthalene-1,5-diol (L2), and 4-amino-3-hydroxynaphthalene-1-sulphonic acid (L3) were characterized from $\mathrm{pH}$-metric measurements in pure water and in different concentrations $\left(0-4 \mathrm{~mol} \mathrm{~kg}^{-1}\right)$ of aqueous $\mathrm{KCl}$ solutions at the temperature range of $T=(293.15$ to 213.15$) \mathrm{K}$ at $5 \mathrm{~K}$ intervals. The results reveal that naphthalen-1-ol and naphthalene-1,5-diol molecules have two ionisable protons (of the hydroxyl groups) while 4-amino-3-hydroxynaphthalene-1sulphonic acid has three ionisable protons (hydrogen ion of the hydroxyl group, $\mathrm{SO}_{3} \mathrm{H}$, and $\mathrm{NH}_{3}{ }^{+}$). Modeling of the data was done by applying Debye-Hückel model. The protonation and the solvation processes of all studied ligands are spontaneous and endothermic processes. Also the solubilities of naphthalen-1-ol, naphthalene-1,5-diol, and 4-amino-3-hydroxynaphthalene-1-sulphonic acid were determined. The data were analyzed using Setschenow equation and the values of Setschenow coefficients $\left(k_{m}\right)$ were determined. From the solubility data, the activity coefficients were obtained. The values of the total solubilities $\left(S^{\mathrm{T}}\right)$ for naphthalen-1-ol and naphthalene-1,5-diol were found equal to the values of their neutral species $\left(S^{0}\right)$. On the other hand, the total solubility for 4-amino3-hydroxynaphthalene-1-sulphonic acid is different from that of its neutral species. The results also indicate solubility decrease in pure water from L1-L2-L3.
\end{abstract}

\section{Introduction}

Naphthols are used in the manufacturing of dyes (where they are classified as fast dyes, with characteristic colors, and usually slightly cheaper than vat dyeing) and other important compounds and as a ligand in the transition-metal catalysts $[1,2]$. Naphthols can be used in many organic syntheses $[3,4]$. Also it was found that naphthol is used to decrease testosterone levels in adult men $[5,6]$ and to stain collagen in histology [7]. Moreover it is used for polychrome stains with animal tissue. For industry purposes naphthol is used for staining wool, nylon, paper, an oxidized aluminum, and soap [7]. Naphthols are pollutants as a result of their slow degradation.

The study of the solubilities and the acid-base properties of naphthalen-1-ol, naphthalene-1,5-diol, and 4-amino-3hydroxynaphthalene-1-sulphonic acid is very useful for both the industrial and the environmental purpose. The purpose of the present work is to study the solubilities (one of the most important physicochemical parameters) and the protonation constants of naphthalen-1-ol, naphthalene-1,5-diol, and 4amino-3-hydroxynaphthalene-1-sulphonic acid in pure and in aqueous potassium chloride solutions of different ionic strengths at the temperature range of $T=(293.15$ to 213.15$) \mathrm{K}$ at $5 \mathrm{~K}$ intervals.

\section{Experimental}

2.1. Materials and Solutions. Potassium chloride (99.5\%) (BDH, England) was used after drying at $T=383.15 \mathrm{~K}$. Sodium hydroxide (99.5\%) (Fluka, puriss, electrochemical grade) was used. Carbonate-free $\mathrm{KOH}$ solution was also prepared and standardized against oxalic acid. Hydrochloric acid (36.5\%) (Fluka) solution was prepared and standardized against sodium carbonate. The ligands, naphthalen1-ol (99.0\%), naphthalene-1,5-diol (99.5\%), and 4-amino3-hydroxynaphthalene-1-sulphonic acid (99.0\%) (Scheme 1), were used as supplied from Aldrich. All solutions were prepared in double-distilled water. Soda lime was used to preserve all solutions from atmospheric $\mathrm{CO}_{2}$. 
<smiles>Oc1cccc2ccccc12</smiles>

Naphthalen-1-ol (L1)<smiles>Oc1cccc2c(O)cccc12</smiles>

Naphthalene-1,5-diol (L2)<smiles>Nc1c(O)cc(S(=O)(=O)O)c2ccccc12</smiles>

4-Amino-3-hydroxynaphthalene1-sulphonic acid (L3)

Scheme 1: The chemical structure of the studied naphthalene derivatives.

2.2. Apparatus and Procedure. A pH meter of type Mettler Toledo MP 220, connected to a Metrohm 665 automatic burette and to a model 8101 Ross type Orion electrode, coupled with a standard calomel electrode was used for the $\mathrm{pH}$-metric measurements with uncertainty $\pm 0.05 \mathrm{mV}$. Thermostated acidic buffer $\mathrm{pH} 4$, neutral buffer $\mathrm{pH} 7$, and basic buffer $\mathrm{pH} 10$ solutions, containing the same concentration of potassium chloride (same ionic strength), were used for the standardization processes of the $\mathrm{pH}$ meter. The temperature was controlled at the proper degree $(293.15,298.15,303.15$, 308.15 , and 313.15$) \pm 0.05 \mathrm{~K}$ using Ultrathermostate of type MLW Prüfgeräte-Werk.

Saturated solutions of the studied ligands (L1, L2, and L3) were prepared where an excess amount of ligand was added to pure water or to potassium chloride solutions of different ionic strengths from 0 to $4 \mathrm{~mol} \mathrm{~kg}^{-1}$. Solutions were then stirred for at least $24 \mathrm{~h}$ at the proper constant temperature $(293.15,298.15,303.15,308.15$, and 313.15$) \mathrm{K}$. The equilibrium state was reached after $5-7 \mathrm{~h}$ of stirring as indicated from the conductivity measurements of the saturated solutions. Cellulose membrane was used for the filtration process of the centrifuged saturated solutions, and then standard $\mathrm{KOH}$ solution was used for titration processes of the filtered solutions. The titrated solutions were under magnetic stirring. In order to remove $\mathrm{O}_{2}$ and $\mathrm{CO}_{2}$, purified $\mathrm{N}_{2}$ was bubbled through the solution. Titrand solutions were prepared and $\mathrm{pH}$ measurements were performed as reported earlier [8, 9]. The reported data are the mean of three independent experiments.

\section{Results and Discussion}

3.1. Protonation Constants. The $\mathrm{pH}$ measurements for the ligands under study (naphthalen-1-ol, naphthalene-1,5-diol, and 4-amino-3-hydroxynaphthalene-1-sulphonic acid) in aqueous solution, at the temperature range of $T=(293.15$ to 213.15) $\mathrm{K}$ at $5 \mathrm{~K}$ intervals, were performed as reported earlier $[8,9]$. The number of protons associated with the molecules of the ligands under study, $n_{A}$, was calculated as reported earlier [10].

The maximum $n_{A}$ values measured in case of the ligands in the selected conditions has been found to be $\sim 0.9$ for naphthalen-1-ol, $\sim 1.9$ for naphthalene-1,5-diol, and 2.85 for 4-amino-3-hydroxynaphthalene-1-sulphonic acid revealing that the 1-naphthol has one ionisable hydrogen atom and 1,5 dihydroxynaphthalene molecule has two ionisable
TABLE 1: Experimental protonation constant $\left(\log K^{\mathrm{H}}{ }_{1} \pm 0.01\right)$ of $\mathrm{Ll}$, in $\mathrm{KCl}$ of different ionic strength and at different temperatures.

\begin{tabular}{cccccc}
\hline$m_{\mathrm{KCl}}$ & $293.15 \mathrm{~K}$ & $298.15 \mathrm{~K}$ & $303.15 \mathrm{~K}$ & $308.15 \mathrm{~K}$ & $313.15 \mathrm{~K}$ \\
\hline 0.000 & 9.22 & $9.25(9.41)$ & 9.19 & 9.17 & 9.16 \\
0.010 & 9.19 & 9.18 & 9.17 & 9.16 & 9.15 \\
0.250 & 9.21 & 9.20 & 9.18 & 9.17 & 9.16 \\
0.950 & 9.26 & 9.24 & 9.23 & 9.21 & 9.20 \\
1.900 & 9.30 & 9.29 & 9.27 & 9.26 & 9.25 \\
2.300 & 9.40 & 9.38 & 9.37 & 9.36 & 9.35 \\
3.100 & 9.49 & 9.48 & 9.46 & 9.45 & 9.44 \\
\hline
\end{tabular}

Values in parentheses are the literature [11] protonation constants.

hydrogen atoms of the hydroxyl groups while 1-amino2-naphthol-4-sulphonic acid has three ionisable hydrogen atoms of the hydroxyl group, sulphonic group $\left(\mathrm{SO}_{3} \mathrm{H}\right)$, and amino group $\left(\mathrm{NH}_{3}{ }^{+}\right)$. The protonation constants of naphthalen-1-ol and naphthalene-1,5-diol and 2.85 for 4amino-3-hydroxynaphthalene-1-sulphonic acid were calculated by applying the interpolation half method [11]. ESAB2M program [12] was used for recalculation of the protonation constants of naphthalen-1-ol and naphthalene-1,5-diol and 2.85 for 4-amino-3-hydroxynaphthalene-1-sulphonic acid.

The experimental protonation constants along with the literature [13] values of naphthalen-1-ol, naphthalene-1,5diol, and 4-amino-3-hydroxynaphthalene-1-sulphonic acid are reported in Tables $1-3$. The $K^{\mathrm{H}}$ is a function of the activity coefficients as reported in (1) for naphthalene-1,5-diol as example:

$$
\begin{aligned}
& \log K_{1}^{\mathrm{H}}=\log K_{1,0}^{\mathrm{H}}+\log K_{\mathrm{H}^{+}}+\log \gamma_{\mathrm{L}^{2-}}-\log \gamma_{\mathrm{HL}^{-}}, \\
& \log K^{\mathrm{H}}{ }_{2}=\log K^{\mathrm{H}}{ }_{2,0}+\log \gamma_{\mathrm{H}^{+}}+\log \gamma_{\mathrm{L}^{-}}-\log \gamma_{\mathrm{H}_{2} \mathrm{~L}^{0}},
\end{aligned}
$$

where $\log K_{n, 0}^{\mathrm{H}}$ is the logarithm of the protonation constant at infinite dilution and $\gamma_{i}$ is the activity coefficient of the $i$ th species. The change in $K^{\mathrm{H}}$ with the solution ionic strength can be shown as presented in Figure 1, for L1 as example. As can be noted from Figure 1, and also from similar figures for $\mathrm{L} 2$ and $\mathrm{L} 3$, the change in $K^{\mathrm{H}}$ with the solution ionic strength for naphthalen-1-ol, and naphthalene-1,5-diol, is similar to the change reported for carboxylates and resorcinols $[14,15]$. On the other hand the change in $K^{\mathrm{H}}$ with the solution ionic strength for 4-amino-3-hydroxynaphthalene1-sulphonic acid shows a quite different behaviour which may 
TABLE 2: Experimental protonation constants $\left(\left(\log K^{\mathrm{H}}{ }_{1} \pm 0.01\right)\right.$ and $\left.\left(\log K^{\mathrm{H}}{ }_{2} \pm 0.02\right)\right)$ of $\mathrm{L} 2$, in $\mathrm{KCl}$ of different ionic strength and at different temperatures $(T / \mathrm{K})$.

\begin{tabular}{|c|c|c|c|c|c|c|c|c|c|c|}
\hline \multirow{2}{*}{$m_{\mathrm{KCl}}$} & \multicolumn{2}{|c|}{293.15} & \multicolumn{2}{|c|}{298.15} & \multicolumn{2}{|c|}{303.15} & \multicolumn{2}{|c|}{308.15} & \multicolumn{2}{|c|}{313.15} \\
\hline & $\log K^{\mathrm{H}}{ }_{1}$ & $\log K^{\mathrm{H}}{ }_{2}$ & $\log K^{\mathrm{H}}{ }_{1}$ & $\log K^{\mathrm{H}}{ }_{2}$ & $\log K^{\mathrm{H}}{ }_{1}$ & $\log K^{\mathrm{H}}{ }_{2}$ & $\log K^{\mathrm{H}}{ }_{1}$ & $\log K^{\mathrm{H}}{ }_{2}$ & $\log K^{\mathrm{H}}{ }_{1}$ & $\log K^{\mathrm{H}}{ }_{2}$ \\
\hline 0.000 & 10.21 & 8.78 & 10.20 & 8.76 & 10.19 & 8.76 & 10.18 & 8.74 & 10.17 & 8.73 \\
\hline 0.460 & 10.24 & 8.75 & 10.23 & 8.75 & 10.22 & 8.74 & 10.21 & 8.73 & 10.20 & 8.73 \\
\hline 0.500 & 10.25 & 8.78 & 10.24 & 8.77 & 10.23 & 8.75 & 10.22 & 8.74 & 10.21 & 8.75 \\
\hline 0.940 & 10.08 & 8.72 & 10.07 & 8.70 & 10.06 & 8.69 & 10.05 & 8.69 & 10.04 & 8.67 \\
\hline 1.500 & 10.04 & 8.73 & 10.03 & 8.72 & 10.02 & 8.72 & 10.01 & 8.70 & 10.00 & 8.69 \\
\hline 2.000 & 10.07 & 8.81 & 10.06 & 8.80 & 10.05 & 8.80 & 10.04 & 8.78 & 10.03 & 8.77 \\
\hline 2.100 & 10.08 & 8.84 & 10.09 & 8.82 & 10.06 & 8.81 & 10.05 & 8.81 & 10.04 & 8.79 \\
\hline 3.200 & 10.28 & 8.95 & 10.27 & 8.95 & 10.26 & 8.94 & 10.25 & 8.93 & 10.24 & 8.91 \\
\hline
\end{tabular}

TABLE 3: Experimental protonation constants $\left(\left(\log K^{\mathrm{H}}{ }_{1} \pm 0.02\right)\right.$, $\left(\log K_{2}^{\mathrm{H}} \pm 0.02\right)$, and $\left.\left(\log \mathrm{K}_{3}^{\mathrm{H}} \pm 0.07\right)\right)$ of $\mathrm{L} 3$, in $\mathrm{KCl}$ of different ionic strength and at different temperatures.

\begin{tabular}{|c|c|c|c|c|c|c|}
\hline$m_{\mathrm{KCl}}$ & $\log K_{n}^{\mathrm{H}}$ & $293.15 \mathrm{~K}$ & $298.15 \mathrm{~K}$ & $303.15 \mathrm{~K}$ & $308.15 \mathrm{~K}$ & $313.15 \mathrm{~K}$ \\
\hline & $\log K^{\mathrm{H}}{ }_{1}$ & 10.27 & 10.25 & 10.24 & 10.23 & 10.21 \\
\hline \multirow[t]{2}{*}{0.000} & $\log K^{\mathrm{H}}{ }_{2}$ & 8.15 & $8.05(8.80)$ & 8.03 & 8.01 & 8.00 \\
\hline & $\log K^{\mathrm{H}}{ }_{3}$ & 1.23 & $1.22(3.10)$ & 1.20 & 1.18 & 1.17 \\
\hline \multirow{3}{*}{0.005} & $\log K^{\mathrm{H}}{ }_{1}$ & 9.83 & 9.80 & 9.78 & 9.77 & 9.75 \\
\hline & $\log K^{\mathrm{H}}{ }_{2}$ & 8.11 & 8.08 & 8.07 & 8.05 & 8.04 \\
\hline & $\log K^{\mathrm{H}}{ }_{3}$ & 1.25 & 1.24 & 1.23 & 1.21 & 1.19 \\
\hline \multirow{3}{*}{0.163} & $\log K^{\mathrm{H}}{ }_{1}$ & 9.89 & 9.86 & 9.84 & 9.83 & 9.81 \\
\hline & $\log K^{\mathrm{H}}{ }_{2}$ & 8.22 & 8.19 & 8.17 & 8.15 & 8.14 \\
\hline & $\log K^{\mathrm{H}}{ }_{3}$ & 1.37 & 1.35 & 1.34 & 1.32 & 1.31 \\
\hline \multirow{3}{*}{0.521} & $\log K^{\mathrm{H}}{ }_{1}$ & 9.87 & 9.84 & 9.83 & 9.81 & 9.80 \\
\hline & $\log K^{\mathrm{H}}{ }_{2}$ & 8.23 & 8.20 & 8.20 & 8.19 & 8.17 \\
\hline & $\log K^{\mathrm{H}}{ }_{3}$ & 1.53 & 1.49 & 1.49 & 1.47 & 1.45 \\
\hline \multirow{3}{*}{0.941} & $\log K^{\mathrm{H}}{ }_{1}$ & 9.91 & 9.89 & 9.87 & 9.85 & 9.83 \\
\hline & $\log K^{\mathrm{H}}{ }_{2}$ & 8.23 & 8.22 & 8.22 & 8.20 & 8.18 \\
\hline & $\log K_{3}^{\mathrm{H}}$ & 1.81 & 1.79 & 1.79 & 1.77 & 1.76 \\
\hline \multirow{3}{*}{1.940} & $\log K_{1}^{\mathrm{H}}$ & 10.37 & 10.35 & 10.33 & 10.31 & 10.30 \\
\hline & $\log K^{\mathrm{H}}{ }_{2}$ & 8.53 & 8.51 & 8.50 & 8.48 & 8.47 \\
\hline & $\log K^{\mathrm{H}}{ }_{3}$ & 1.98 & 1.96 & 1.95 & 1.93 & 1.92 \\
\hline \multirow{3}{*}{2.701} & $\log K^{\mathrm{H}}{ }_{1}$ & 10.84 & 10.83 & 10.81 & 10.79 & 10.77 \\
\hline & $\log K_{2}^{\mathrm{H}}$ & 8.87 & 8.85 & 8.84 & 8.82 & 8.81 \\
\hline & $\log K_{3}^{\mathrm{H}}$ & 2.47 & 2.45 & 2.43 & 2.41 & 2.40 \\
\hline \multirow{3}{*}{3.702} & $\log K^{\mathrm{H}}{ }_{1}$ & 11.37 & 11.36 & 11.34 & 11.32 & 11.31 \\
\hline & $\log K^{\mathrm{H}}{ }_{2}$ & 9.18 & 9.16 & 9.15 & 9.13 & 9.10 \\
\hline & $\log K^{\mathrm{H}}{ }_{3}$ & 3.50 & 3.47 & 3.46 & 3.44 & 3.41 \\
\hline
\end{tabular}

Values in parentheses are the literature [11] protonation constants.

be due to the presence of $\left(\mathrm{SO}_{3} \mathrm{H}\right)$ and $\left(\mathrm{NH}_{3}{ }^{+}\right)$groups. This behavior may be due to the effect of the ligands-supporting electrolyte mutual interactions and the relation between the protonation constants and the ionic strength of the solution. The ligands-supporting electrolyte mutual interactions have opposite effect on the carboxylate, resorcinol, and amino groups.

On comparing the effect of $\mathrm{KCl}$ on the protonation constant of the naphthols compounds under study with that

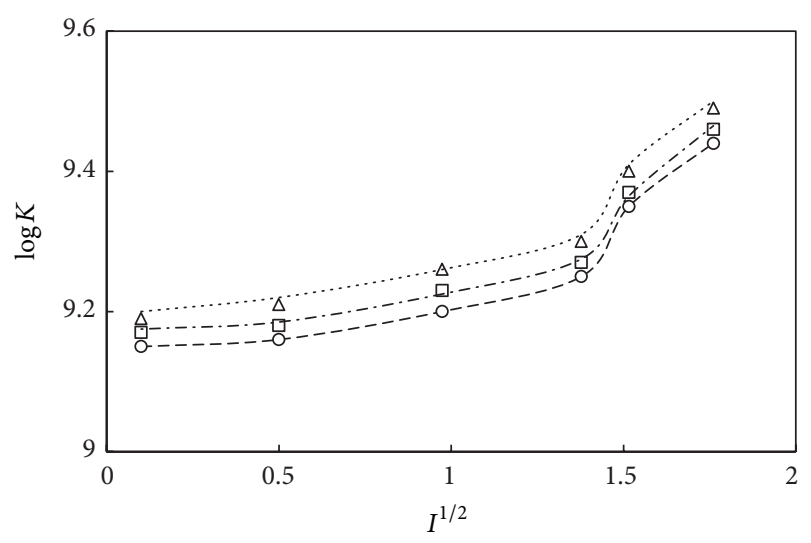

FIGURE 1: Dependence of the protonation constant on ionic strength in $\mathrm{KCl}$, for 1-naphthol: the experimental values are $293.15 \mathrm{~K}(\triangle)$, $303.15 \mathrm{~K}(\square)$, and $313.15 \mathrm{~K}(\bigcirc)$ and the model values are expressed in dotted lines.

of $\mathrm{NaCl}$ on the same naphthols [9], we can note that the effect of $\mathrm{NaCl}$ may be identical to that of $\mathrm{KCl}$. This can be shown from the nearly equal values of the parameters $c_{\infty}$ and $c_{0}$ at $298.15 \mathrm{~K}$.

3.2. Modeling of the Data. The change in $K^{\mathrm{H}}$ with the ionic strength was studied according to Debye-Hückel model [14] as shown in

$$
\log K^{\mathrm{H}}{ }_{1}=\log K^{\mathrm{H}}{ }_{1,0}-0.5 z^{*}\left(\frac{I^{1 / 2}}{1+1.5 I^{1 / 2}}\right)+C(I),
$$

where $z^{*}=\sum z^{2}$ react $-z^{2}$ prod and $C(I)$ depends on the ionic strength as shown in the following equation:

$$
C=c_{\infty}+\left[\frac{\left(c_{0}-c_{\infty}\right)}{(I+1)}\right] .
$$

The change in $K^{\mathrm{H}}$ with the solution ionic strength was indicated from the values of the parameters $c_{\infty}$ and $c_{0}$ which reported for ionic strength $=\infty$ and ionic strength $=0$, respectively. The same equation for $C$ is reported earlier $[16,17]$ and it can be used up to ionic strength $=6 \mathrm{~mol} \cdot \mathrm{kg}^{-1}$. The values of the protonation constant at infinite dilution and 
TABLE 4: The protonation constants at infinite dilution $\left(\log K^{\mathrm{H}^{0}}{ }_{n} \pm\right.$ 0.001 ) and parameters $\left(c_{0}\right.$ and $c_{\infty}$ ) for the dependence of the protonation constants on ionic strength for L1, L2, and L3 at different temperatures.

\begin{tabular}{|c|c|c|c|c|c|c|}
\hline $\mathrm{Liq}$ & $\log K^{\mathrm{H}^{0}}{ }_{n}$ & $293.15 \mathrm{~K}$ & $298.15 \mathrm{~K}$ & $303.15 \mathrm{~K}$ & $308.15 \mathrm{~K}$ & $313.15 \mathrm{~K}$ \\
\hline \multirow{3}{*}{ L1 } & $\log K^{\mathrm{H}^{0}}$ & 9.46 & 9.45 & 9.44 & 9.42 & 9.40 \\
\hline & $c_{0}$ & 0.27 & 0.26 & 0.28 & 0.26 & 0.27 \\
\hline & $c_{\infty}$ & 0.02 & 0.02 & 0.03 & 0.02 & 0.03 \\
\hline \multirow{6}{*}{$\mathrm{L} 2$} & $\log K^{\mathrm{H}^{0}}$ & 10.19 & 10.17 & 10.16 & 10.14 & 10.13 \\
\hline & $c_{0}$ & 0.38 & 0.36 & 0.37 & 0.36 & 0.37 \\
\hline & $c_{\infty}$ & 0.95 & 0.93 & 0.93 & 0.95 & 0.94 \\
\hline & $\log K^{\mathrm{H}^{0}}$ & 8.89 & 8.86 & 8.85 & 8.84 & 8.82 \\
\hline & $c_{0}$ & 0.25 & 0.23 & 0.24 & 0.23 & 0.24 \\
\hline & $c_{\infty}$ & 0.21 & 0.26 & 0.23 & 0.25 & 0.21 \\
\hline \multirow{9}{*}{ L3 } & $\log K^{\mathrm{H}^{0}}$ & 10.37 & 10.35 & 10.33 & 10.32 & 10.30 \\
\hline & $c_{0}$ & 0.77 & 0.75 & 0.73 & 0.72 & 0.77 \\
\hline & $c_{\infty}$ & 0.09 & 0.08 & 0.07 & 0.08 & 0.09 \\
\hline & $\log K^{\mathrm{H}^{0}}{ }_{2}$ & 8.46 & 8.44 & 8.42 & 8.43 & 8.40 \\
\hline & $c_{0}$ & 0.46 & 0.48 & 0.49 & 0.49 & 0.50 \\
\hline & $c_{\infty}$ & 0.03 & 0.02 & 0.03 & 0.02 & 0.01 \\
\hline & $\log K^{\mathrm{H}^{0}}{ }_{3}$ & 1.31 & 1.29 & 1.27 & 1.26 & 1.24 \\
\hline & $c_{0}$ & 0.48 & 0.45 & 0.43 & 0.46 & 0.46 \\
\hline & $c_{\infty}$ & 0.02 & 0.02 & 0.03 & 0.02 & 0.03 \\
\hline
\end{tabular}

the values of the parameters $c_{\infty}$ and $c_{0}$ for the three ligands under study at different temperatures are recorded in Table 4.

3.3. Solubility Measurements. According to the association processes of naphthalen-1-ol, naphthalene-1,5-diol, and 4Amino-3-hydroxynaphthalene-1-sulphonic acid, the following equilibrium can be established. The total solubility $\left(S^{\mathrm{T}}\right)$ for naphthalen-1-ol, naphthalene-1,5-diol, and 4-amino-3hydroxynaphthalene-1-sulphonic acid was considered equal to the summation of the neutral and deprotonated or partially protonated species in solution, as follows:

$$
\begin{aligned}
\mathrm{H}^{+}+\mathrm{L}^{-} & \longleftrightarrow \mathrm{HL} \\
S^{\mathrm{T}} & =\left[\mathrm{HL}^{0}\right]+\left[\mathrm{L}^{-}\right] \\
\mathrm{H}^{+}+\mathrm{L}^{-2} & \longleftrightarrow \mathrm{HL}^{-} \\
\mathrm{HL}^{-}+\mathrm{H}^{+} & \longleftrightarrow \mathrm{H}_{2} \mathrm{~L} \\
S^{\mathrm{T}} & =\left[\mathrm{H}_{2} \mathrm{~L}^{0}\right]+\left[\mathrm{HL}^{-}\right]+\left[\mathrm{L}^{2-}\right] \\
\mathrm{H}^{+}+\mathrm{L}^{-2} & \longleftrightarrow \mathrm{HL}^{-} \\
\mathrm{HL}^{-}+\mathrm{H}^{+} & \longleftrightarrow \mathrm{H}_{2} \mathrm{~L} \\
\mathrm{H}_{2} \mathrm{~L}+\mathrm{H}^{+} & \longleftrightarrow \mathrm{H}_{3} \mathrm{~L}^{+} \\
S^{\mathrm{T}} & =\left[\mathrm{H}_{3} \mathrm{~L}^{+}\right]+\left[\mathrm{H}_{2} \mathrm{~L}^{0}\right]+\left[\mathrm{HL}^{-}\right]+\left[\mathrm{L}^{2-}\right]
\end{aligned}
$$

(For (6) and (7) see [18] and for (9), (10), and (11) see [19]), where $\left[\mathrm{HL}^{0}\right]$ and $\left[\mathrm{H}_{n} \mathrm{~L}^{0}\right]$ are the solubility of the neutral species, $S^{0}$, for naphthalen-1-ol and naphthalene-1,5-diol/4amino-3-hydroxynaphthalene-1-sulphonic acid, respectively. For the above equilibrium, $K^{\mathrm{H}}$ for naphthalen-1-ol, naphthalene-1,5-diol, and 4-amino-3-hydroxynaphthalene1-sulphonic acid was considered as follows:

$$
\begin{aligned}
K^{\mathrm{H}}{ }_{1} & =\frac{\left[\mathrm{HL}^{0}\right]}{\left[\mathrm{H}^{+}\right]\left[\mathrm{L}^{-}\right]} \\
K^{\mathrm{H}} & =\frac{\left[\mathrm{HL}^{-}\right]}{\left[\mathrm{H}^{+}\right]\left[\mathrm{L}^{2-}\right]} \\
K^{\mathrm{H}}{ }_{2} & =\frac{\left[\mathrm{H}_{2} \mathrm{~L}^{0}\right]}{\left[\mathrm{H}^{+}\right]\left[\mathrm{HL}^{-}\right]} \\
K^{\mathrm{H}} & =\frac{\left[\mathrm{HL}^{-}\right]}{\left[\mathrm{H}^{+}\right]\left[\mathrm{L}^{2-}\right]} \\
K^{\mathrm{H}}{ }_{1} & =\frac{\left[\mathrm{H}_{2} \mathrm{~L}^{0}\right]}{\left[\mathrm{H}^{+}\right]\left[\mathrm{HL}^{-}\right]} \\
K^{\mathrm{H}}{ }_{2} & =\frac{\left[\mathrm{H}_{3} \mathrm{~L}^{+}\right]}{\left[\mathrm{H}^{+}\right]\left[\mathrm{H}_{2} \mathrm{~L}^{0}\right]} .
\end{aligned}
$$

The values of the neutral species solubility, $S^{0}$, can be calculated by considering (5)-(15c) as follows:

$$
\begin{aligned}
S^{\mathrm{T}} & =S^{0}\left\{1+\left(\frac{1}{K^{\mathrm{H}}{ }_{1}\left[\mathrm{H}^{+}\right]}\right)\right\} \\
S^{\mathrm{T}} & =S^{0}\left\{1+\left(\frac{1}{K^{\mathrm{H}}{ }_{2}\left[\mathrm{H}^{+}\right]}\right)+\left(\frac{1}{K^{\mathrm{H}}{ }_{1} K^{\mathrm{H}}{ }_{2}\left[\mathrm{H}^{+}\right]^{2}}\right)\right\} \\
S^{\mathrm{T}} & =S^{0}\left\{1+\left(\frac{1}{K^{\mathrm{H}}{ }_{2}\left[\mathrm{H}^{+}\right]}\right)+\left(\frac{1}{K^{\mathrm{H}}{ }_{1} K^{\mathrm{H}}{ }_{2}\left[\mathrm{H}^{+}\right]^{2}}\right)\right. \\
& \left.+\left(K^{\mathrm{H}}{ }_{3}\left[\mathrm{H}^{+}\right]\right)\right\} .
\end{aligned}
$$

The values of the total solubilities $\left(S^{\mathrm{T}}\right)$ for naphthalen-1-ol and naphthalene-1,5-diol were found equal to that of their neutral species $\left(S^{0}\right)$. The values of the total solubilities $\left(S^{\mathrm{T}}\right)$ for L1 and L2 or those of their neutral species $\left(S^{0}\right)$ were reported in Table 5. On the other hand, the total solubility for L3 is different from that of its neutral species, calculated from (18), as reported in Table 6.

The effect of $\mathrm{KCl}$ salt concentration on the solubility of the studied naphthols was studied by fitting the total molal solubility $\left(S^{\mathrm{T}}\right)$ of the naphthol against the $\mathrm{KCl}$ salt concentration $\left(m_{\mathrm{MX}}\right)$ (e.g., Figure 2 ) as expressed in the following equation:

$$
\log S^{\mathrm{T}}=\log S_{0}^{\mathrm{T}}+a \cdot m_{\mathrm{MX}}
$$

where $S^{\mathrm{T}}{ }_{0}$ and $S^{\mathrm{T}}$ are the total molal solubility of the studied naphthols in pure water (i.e., at infinite dilution where $m_{\mathrm{MX}}$ $=0.00)$ and in different $\mathrm{KCl}$ salt concentrations, $m_{\mathrm{MX}}$ is the molal concentration of $\mathrm{KCl}$ salt, and (a) represents the linear 
TABLE 5: Total molal solubilities $S^{\mathrm{T}} \times 10^{-3}, \mathrm{~mol} / \mathrm{kg}^{-1}$ (or molal solubilities of neutral species, $S^{0} \times 10^{-3}, \mathrm{~mol} / \mathrm{kg}^{-1}$ ), of L1 and L2 at different ionic strength in aqueous $\mathrm{KCl}$ and at different temperatures.

\begin{tabular}{|c|c|c|c|c|c|c|}
\hline Ligand & $m_{\mathrm{KCl}}$ & $293.15 \mathrm{~K}$ & $298.15 \mathrm{~K}$ & $303.15 \mathrm{~K}$ & $308.15 \mathrm{~K}$ & $313.15 \mathrm{~K}$ \\
\hline \multirow{7}{*}{ L1 } & 0.000 & $9.572(9.530)$ & $10.106(10.092)$ & $10.563(10.544)$ & 11.175 (11.168) & 11.705 (11.695) \\
\hline & 0.010 & 9.333 & 9.772 & 10.233 & 10.965 & 11.220 \\
\hline & 0.250 & 8.709 & 9.333 & 9.772 & 10.233 & 10.965 \\
\hline & 0.950 & 6.309 & 6.607 & 6.761 & 7.244 & 7.586 \\
\hline & 1.900 & 3.890 & 4.169 & 4.365 & 4.467 & 4.786 \\
\hline & 2.300 & 3.236 & 3.388 & 3.548 & 3.715 & 3.802 \\
\hline & 3.100 & 2.399 & 2.512 & 2.570 & 2.754 & 2.884 \\
\hline$a$ & & -0.198 & -0.199 & -0.200 & -0.201 & -0.202 \\
\hline \multirow{8}{*}{ L2 } & 0.000 & $1.212(1.219)$ & $1.259(1.265)$ & $1.316(1.321)$ & $1.379(1.384)$ & $1.442(1.449)$ \\
\hline & 0.460 & 1.047 & 1.072 & 1.122 & 1.175 & 1.230 \\
\hline & 0.500 & 1.000 & 1.047 & 1.096 & 1.148 & 1.202 \\
\hline & 0.940 & 0.891 & 0.933 & 0.977 & 1.023 & 1.096 \\
\hline & 1.500 & 0.758 & 0.794 & 0.832 & 0.871 & 0.912 \\
\hline & 2.000 & 0.575 & 0.603 & 0.631 & 0.661 & 0.692 \\
\hline & 2.100 & 0.525 & 0.575 & 0.603 & 0.631 & 0.661 \\
\hline & 3.200 & 0.407 & 0.427 & 0.447 & 0.468 & 0.489 \\
\hline$a$ & & -0.153 & -0.151 & -0.151 & -0.150 & -0.149 \\
\hline
\end{tabular}

Values in parentheses are the total molal solubilities at infinite dilution $\left(\left(S^{\mathrm{T}}{ }_{0}\right)\right.$ or $\left.\left(S^{0}{ }_{0}\right)\right)$ estimated from the extrapolation of the plot of $m_{\mathrm{KCl}}$ versus $\log S^{\mathrm{T}}$ to zero $m_{\mathrm{KCl}}$.

TABLE 6: Total solubilities $S^{\mathrm{T}} \times 10^{-3}, \mathrm{~mol} / \mathrm{kg}^{-1}$ (and solubilities of neutral species, $S^{0} \times 10^{-3}, \mathrm{~mol} / \mathrm{kg}^{-1}$ ), of L3 at different ionic strength of aqueous $\mathrm{KCl}$ and at different temperatures.

\begin{tabular}{lcccccccccc}
\hline \multirow{2}{*}{$m_{\mathrm{KCl}}$} & \multicolumn{2}{c}{$293.15 \mathrm{~K}$} & \multicolumn{2}{c}{$298.15 \mathrm{~K}$} & \multicolumn{2}{c}{$303.15 \mathrm{~K}$} & \multicolumn{2}{c}{$308.15 \mathrm{~K}$} & \multicolumn{2}{c}{$313.15 \mathrm{~K}$} \\
& $S^{\mathrm{T}}$ & $S^{0}$ & $S^{\mathrm{T}}$ & $S^{0}$ & $S^{\mathrm{T}}$ & $S^{0}$ & $S^{\mathrm{T}}$ & $S^{0}$ & $S^{\mathrm{T}}$ & $S^{0}$ \\
\hline \multirow{2}{*}{0.000} & 2.400 & 2.255 & 2.465 & 2.458 & 2.593 & 2.575 & 2.699 & 2.705 & 2.827 & 2.949 \\
& $2.410^{*}$ & $2.265^{*}$ & $2.472^{*}$ & $2.466^{*}$ & $2.588^{*}$ & $2.582^{*}$ & $2.710^{*}$ & $2.716^{*}$ & $2.838^{*}$ & $2.958^{*}$ \\
0.005 & 2.570 & 2.042 & 2.692 & 2.239 & 2.818 & 2.344 & 2.951 & 2.455 & 3.020 & 2.692 \\
0.163 & 2.291 & 1.905 & 2.399 & 2.138 & 2.512 & 2.239 & 2.630 & 2.344 & 2.754 & 2.570 \\
0.521 & 2.138 & 1.738 & 2.188 & 1.820 & 2.239 & 1.905 & 2.344 & 2.042 & 2.455 & 2.188 \\
0.941 & 1.905 & 1.175 & 1.950 & 1.288 & 2.042 & 1.380 & 2.138 & 1.413 & 2.239 & 1.549 \\
1.940 & 1.549 & 1.047 & 1.585 & 1.096 & 1.659 & 1.148 & 1.739 & 1.202 & 1.819 & 1.259 \\
2.701 & 1.349 & 0.240 & 1.413 & 0.245 & 1.479 & 0.257 & 1.549 & 0.269 & 1.622 & 0.282 \\
3.702 & 1.148 & 0.209 & 1.202 & 0.229 & 1.259 & 0.240 & 1.318 & 0.251 & 1.349 & 0.275 \\
\hline$a$ & -0.091 & & -0.089 & & -0.089 & & -0.089 & & -0.092 \\
\hline
\end{tabular}

${ }^{*}$ The total molal solubilities at infinite dilution $\left(S^{\mathrm{T}}{ }_{0}\right)$ and the total molal solubilities of neutral species at infinite dilution $\left(S^{0}{ }_{0}\right)$ estimated from the extrapolation of the plot of $m_{\mathrm{KCl}}$ versus $\log S^{\mathrm{T}}$ and $\log S^{0}$, respectively, to zero $m_{\mathrm{KCl}}$.

parameter (Tables 5 and 6). The solubility of the ligands under study follows the order naphthalen-1-ol > 4-amino3-hydroxynaphthalene-1-sulphonic acid > naphthalene-1,5diol, as shown in Figure 2. The determined values of $S^{\mathrm{T}}{ }_{0}$ from the fitting of (20) were found to be nearly the same values determined experimentally.

The activity coefficients $(\gamma)$ of the studied naphthols, in the molal concentration scale, were calculated [20] applying the following equation:

$$
\log \gamma=\log \left(\frac{S_{0}^{0}}{S^{0}}\right)=k_{m} \cdot m_{\mathrm{MX}},
$$

where $S^{0}$ and $S^{0}$ are the molal solubilities of the neutral species of the studied naphthols, in pure water (i.e., in pure water, where $\left.m_{\mathrm{MX}}=0.00\right)$ and in different $\mathrm{KCl}$ salt concentrations, respectively, and $k_{m}$ is the Setschenow coefficient $[21,22]$. At infinite dilution the activity coefficients are equal to the unity where the solubility $S$ is $<0.05 \mathrm{~mol} \mathrm{~kg}^{-1}$, and there are no ligand self-interactions. Depending on this base, (20) is valid for the present case. Setschenow coefficients were calculated by fitting (20). The Setschenow coefficients and the activity coefficient $(\gamma)$ values were reported in Tables 7 and 8 for naphthalen-1-ol, naphthalene-1,5-diol, and 4amino-3-hydroxynaphthalene-1-sulphonic acid, respectively. 


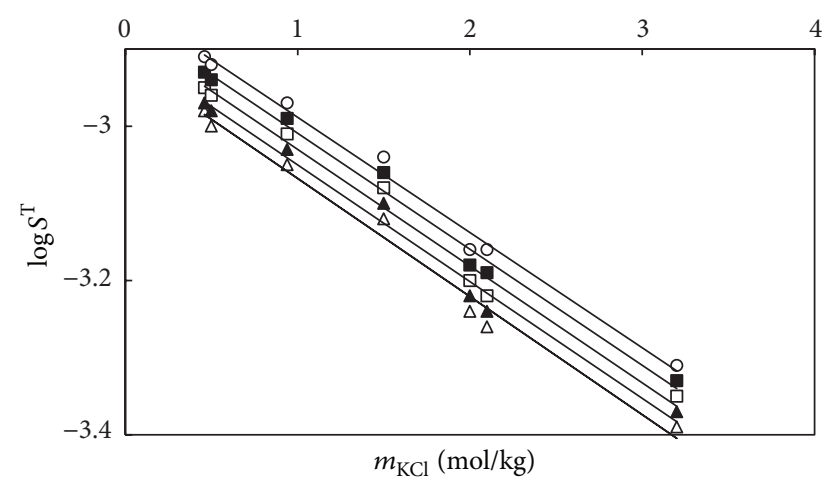

FIGURE 2: Dependence of the total solubility on ionic strength in $\mathrm{KCl}$, for 1,5-dihydroxynaphthalene at $293.15 \mathrm{~K}(\triangle)$, $298.15 \mathrm{~K}(\mathbf{\Delta})$, 303.15 K (口), 308.15 K (匹), and 313.15 K (O).

TABLE 7: Activity coefficients $(\log \gamma)$ and the Setschenow coefficient $\left(k_{m}\right)$ for the neutral species for L1 and L2 in aqueous $\mathrm{KCl}$ of different ionic strength and at different temperatures.

\begin{tabular}{ccccccc}
\hline Ligand & $m_{\mathrm{KCl}}$ & $293.15 \mathrm{~K}$ & $298.15 \mathrm{~K}$ & $303.15 \mathrm{~K}$ & $308.15 \mathrm{~K}$ & $313.15 \mathrm{~K}$ \\
\hline \multirow{4}{*}{$\mathrm{L} 1$} & 0.010 & 0.0091 & 0.0146 & 0.0130 & 0.0080 & 0.0180 \\
& 0.250 & 0.0391 & 0.0346 & 0.0330 & 0.0380 & 0.0279 \\
& 0.950 & 0.1791 & 0.1846 & 0.1930 & 0.1882 & 0.1880 \\
& 1.900 & 0.3891 & 0.3845 & 0.3830 & 0.3980 & 0.3880 \\
& 2.300 & 0.4691 & 0.4746 & 0.4730 & 0.4780 & 0.4880 \\
& 3.100 & 0.5991 & 0.6046 & 0.6131 & 0.6080 & 0.6080 \\
\hline$k_{m}$ & & 0.198 & 0.199 & 0.199 & 0.201 & 0.202 \\
\hline \multirow{4}{*}{$\mathrm{L} 2$} & 0.460 & 0.0660 & 0.0719 & 0.0709 & 0.0711 & 0.0712 \\
& 0.500 & 0.0860 & 0.0821 & 0.0811 & 0.0812 & 0.0812 \\
& 0.940 & 0.1361 & 0.1322 & 0.1310 & 0.1313 & 0.1213 \\
& 1.500 & 0.2063 & 0.2023 & 0.2003 & 0.2011 & 0.2011 \\
& 2.000 & 0.3263 & 0.3218 & 0.3209 & 0.3209 & 0.3210 \\
& 2.100 & 0.3658 & 0.3424 & 0.3406 & 0.3411 & 0.3409 \\
& 3.200 & 0.4764 & 0.4717 & 0.4706 & 0.4709 & 0.4718 \\
\hline$k_{m}$ & & 0.155 & 0.151 & 0.151 & 0.151 & 0.153 \\
\hline
\end{tabular}

Figure 3 shows the change of the activity coefficients with the solution ionic strength for naphthalen-1-ol as example. The same trend for the change of the activity coefficients with the solution ionic strength was noted also for naphthalene-1,5diol, 4-amino-3-hydroxynaphthalene-1-sulphonic acid, and some oxygen-donor ligands $[13,15,20]$. The obtained average Setschenow coefficient $k_{m}$ value $0.21 \pm 0.10$ for the studied ligands is in good agreement with literature average $k_{m}=$ $0.20 \pm 0.10[23,24]$.

\subsection{Thermodynamic Calculations}

3.4.1. Protonation Thermodynamics. The different thermodynamic parameters of the protonation processes, the change in the standard Gibbs free energy, the change in the standard enthalpy, and the change in the standard entropy, were calculated and discussed. The standard Gibbs free energy
TABLE 8: Activity coefficients $(\log \gamma)$ and the Setschenow coefficient $\left(k_{m}\right)$ for the neutral species for $\mathrm{L} 3$ in aqueous $\mathrm{KCl}$ of different ionic strength and at different temperatures.

\begin{tabular}{lccccc}
\hline & $293.15 \mathrm{~K}$ & $298.15 \mathrm{~K}$ & $303.15 \mathrm{~K}$ & $308.15 \mathrm{~K}$ & $313.15 \mathrm{~K}$ \\
\hline 0.005 & 0.0450 & 0.0419 & 0.0420 & 0.0439 & 0.0409 \\
0.163 & 0.0752 & 0.0620 & 0.0619 & 0.0639 & 0.0611 \\
0.521 & 0.1150 & 0.1319 & 0.1321 & 0.1239 & 0.1310 \\
0.941 & 0.2850 & 0.2821 & 0.2721 & 0.2838 & 0.2809 \\
1.940 & 0.3351 & 0.3522 & 0.3520 & 0.3540 & 0.3710 \\
2.701 & 0.9749 & 1.0028 & 1.0020 & 1.0042 & 1.0207 \\
3.702 & 1.0349 & 1.0322 & 1.0317 & 1.0343 & 1.0317 \\
\hline$k_{m}$ & 0.2874 & 0.2871 & 0.2914 & 0.2920 & 0.2940 \\
\hline
\end{tabular}

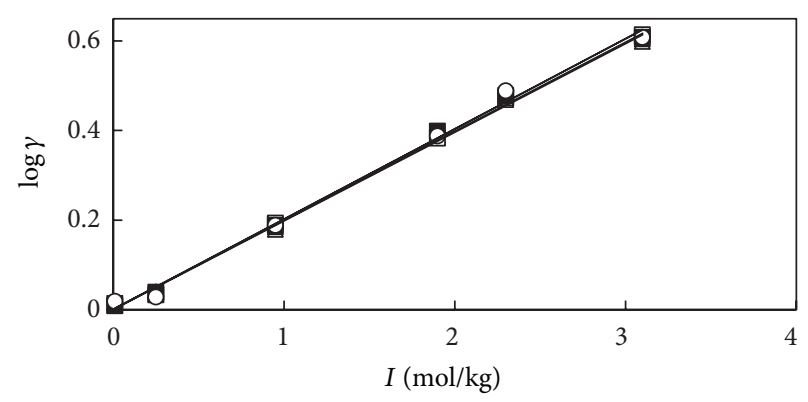

Figure 3: Dependence of $\log \gamma$ on ionic strength in $\mathrm{KCl}$ for 1-

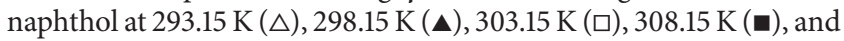
$313.15 \mathrm{~K}(\mathrm{O})$.

change $\left(\Delta G_{n, 0}^{\mathrm{H}}\right)$ was calculated by applying the following equation:

$$
\Delta G_{n, 0}^{\mathrm{H}}=-2.303 R T \log K_{n, 0}^{\mathrm{H}} .
$$

The standard enthalpy change $\Delta H_{n, 0}^{\mathrm{H}}$ and the standard entropy change $\Delta S_{n, 0}^{\mathrm{H}}$ can be calculated using

$$
\Delta G_{n, 0}^{\mathrm{H}}=\Delta H_{n, 0}^{\mathrm{H}}-T\left(\Delta S_{n, 0}^{\mathrm{H}}\right),
$$

where a plot of $\Delta G_{n, 0}^{\mathrm{H}}$ versus $(T)$ gives a straight line with a slope equal to $\left(\Delta S_{n, 0}^{\mathrm{H}}\right)$ and intercept equal to $\Delta H_{n, 0}^{\mathrm{H}}$ (e.g., Figure 4). The values of $\Delta G^{\mathrm{H}}{ }_{n, 0}, \Delta H_{n, 0}^{\mathrm{H}}$, and $\Delta S_{n, 0}^{\mathrm{H}}$ are represented in Table 9. The process of protonation of naphthalen-1-ol, naphthalene-1,5-diol, and 4-amino3-hydroxynaphthalene-1-sulphonic acid is spontaneous and exothermic process as indicated from the negative standard Gibbs free energy changes values and enthalpy change values. These results are in a good agreement with the literature trends $[25,26]$.

3.4.2. Solvation Thermodynamics. The standard Gibbs energy change of the solvation processes of the neutral species at infinite dilution $\left(\Delta G^{\mathrm{S}, 0}{ }_{0}\right)$ was calculated using

$$
\Delta G^{\mathrm{S}, 0}{ }_{0}=-2.303 R T \log K_{\mathrm{SP}} .
$$


TABLE 9: The standard thermodynamic parameters of protonation process $\left(\left(\Delta G_{n, 0}^{\mathrm{H}} \mathrm{kJ} \mathrm{mol}^{-1}\right),\left(\Delta H_{n, 0}^{\mathrm{H}} \mathrm{kJ} \mathrm{mol}^{-1}\right)\right.$, and $\left.\left(\Delta S^{\mathrm{H}}{ }_{n, 0} \mathrm{~kJ} \mathrm{~mol}{ }^{-1} \cdot \mathrm{K}^{-1}\right)\right)$ of L1, L2, and L3 at different temperatures $(T / K)$.

\begin{tabular}{lllllllll}
\hline Ligand & $\Delta G^{\mathrm{H}}{ }_{n, 0}$ & 293.15 & 298.15 & 303.15 & 308.15 & 313.15 & $\Delta H^{\mathrm{H}}{ }_{n, 0} \pm 0.01$ & $\Delta S^{\mathrm{H}}{ }_{n, 0} \pm 0.001$ \\
\hline L1 & $\Delta G^{\mathrm{H}}{ }_{1,0} \pm 0.1$ & -53.018 & -53.866 & -54.712 & -55.497 & -56.278 & -3.721 & 0.169 \\
\hline \multirow{2}{*}{$\mathrm{L} 2$} & $\Delta G^{\mathrm{H}}{ }_{1,0} \pm 0.1$ & -57.110 & -57.970 & -58.888 & -59.739 & -60.649 & -5.258 & 0.177 \\
& $\Delta G^{\mathrm{H}}{ }_{2,0} \pm 0.2$ & -49.824 & -50.503 & -51.293 & -52.080 & -52.806 & -7.474 & 0.144 \\
\hline \multirow{2}{*}{$\mathrm{L} 3$} & $\Delta G^{\mathrm{H}}{ }_{1,0} \pm 0.1$ & -58.118 & -58.996 & -59.870 & -60.799 & -61.667 & -5.962 & 0.178 \\
& $\Delta G^{\mathrm{H}}{ }^{2,0} \pm 0.2$ & -47.414 & -48.109 & -48.800 & -49.665 & -50.291 & -4.557 & 0.146 \\
& $\Delta G^{\mathrm{H}}{ }_{3,0} \pm 0.1$ & -7.342 & -7.353 & -7.361 & -7.423 & -7.424 & -5.963 & 0.005 \\
\hline
\end{tabular}

TABLE 10: The standard thermodynamic parameters of solvation $\left(\left(\Delta G_{0}^{\mathrm{S}}\right.\right.$ and $\left.\Delta H_{0}^{\mathrm{S}} \mathrm{kJ} \mathrm{mol}^{-1}\right)$ and $\left.\left(\Delta S_{0}^{\mathrm{S}} \mathrm{kJ} \mathrm{mol}^{-1} \cdot \mathrm{K}^{-1}\right)\right)$ of L1, $\mathrm{L} 2$, and L3 at different temperatures $(T / K)$.

\begin{tabular}{lccccccc}
\hline Ligand & 293.15 & 298.15 & 303.15 & 308.15 & 313.15 & $\Delta H^{\mathrm{S}}$ & $\Delta S_{0}^{\mathrm{S}}$ \\
\hline L1 & 22.677 & 22.779 & 22.941 & 23.024 & 23.158 & 15.601 & 0.0241 \\
L2 & 45.668 & 46.174 & 46.618 & 47.033 & 47.437 & 19.940 & 0.0879 \\
L3 & 41.141 & 41.209 & 41.553 & 41.849 & 41.863 & 28.894 & 0.0417 \\
\hline
\end{tabular}

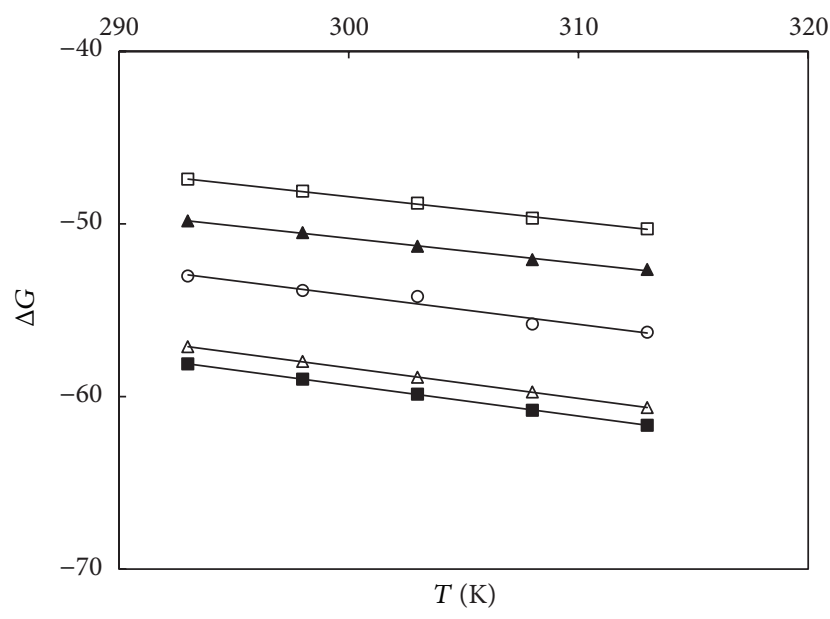

FIgURE 4: Variation of $\Delta G^{\mathrm{H}}{ }_{n, 0}$ with the temperature for $\mathrm{L} 1 \Delta G^{\mathrm{H}}{ }_{1,0}$ (O), $\mathrm{L} 2 \Delta G^{\mathrm{H}}{ }_{1,0}(\Delta)$ and $\Delta G^{\mathrm{H}}{ }_{2,0}(\boldsymbol{\Delta}), \mathrm{L} 3 \Delta G^{\mathrm{H}}{ }_{1,0}(\boldsymbol{\square})$, and $\Delta G^{\mathrm{H}}{ }_{2,0}(\square)$.

The value of $K_{\mathrm{SP}}$ can be calculated using

$$
\begin{aligned}
& \log K_{\mathrm{SP}}=2 \log S_{0}^{0}+2 \log \gamma \quad \text { for L1, } \\
& \log K_{\mathrm{SP}}=\log 4+3 \log S^{0}{ }_{0}+3 \log \gamma
\end{aligned}
$$

for L2 and L3,

where $S_{0}^{0}$ and $\gamma$ are the total molal solubility and the activity coefficient of the neutral species at infinite dilution. The values of the standard enthalpy $\Delta H^{\mathrm{S}, 0}{ }_{0}$ and the standard entropy $\Delta S^{S, 0}{ }_{0}$ of solvation process can be calculated using

$$
\Delta G^{\mathrm{S}, 0}{ }_{0}=\Delta H^{\mathrm{s}, 0}{ }_{0}-T \Delta S^{\mathrm{S}, 0}{ }_{0},
$$

where a plot of $\Delta G^{\mathrm{S}, 0}{ }_{0}$ versus (T) gives a straight line with a slope equal to $\Delta S^{\mathrm{S}, 0}{ }_{0}$ and intercept equal to $\Delta H^{\mathrm{S}, 0}{ }_{0}$ (Figure 5). The values of $\Delta G^{S, 0}{ }_{0}, \Delta H^{S, 0}{ }_{0}$, and $\Delta S^{S, 0}{ }_{0}$ are represented in Table 10. The solvation processes for naphthalen-1-ol,

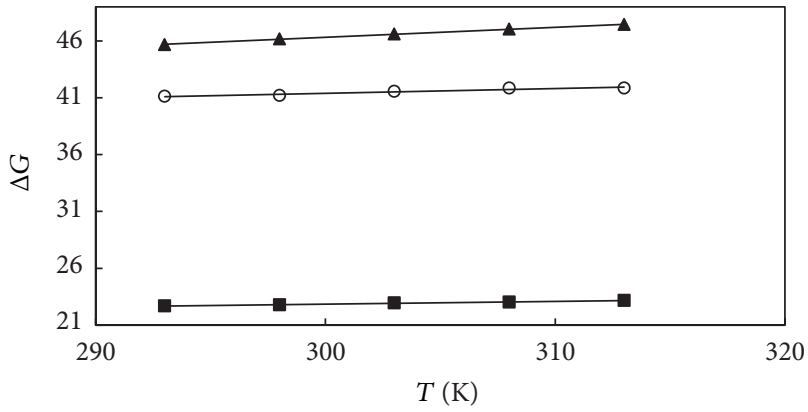

FIGURE 5: Variation of $\Delta G^{\mathrm{S}, 0}{ }_{0}$ with the temperature for L1 (घ), L2 ( $\left.\mathbf{\Delta}\right)$, and L3 $(\mathrm{O})$.

naphthalene-1,5-diol, and 4-amino-3-hydroxynaphthalene-1sulphonic acid are nonspontaneous processes as indicated from the positive standard Gibbs energy changes values. The positive value of $\Delta H^{\mathrm{S}, 0}{ }_{0}$ indicates the endothermic nature of the solvation processes. From Figure 5, it was noted that the solvation free energy of the ligands has the order naphthalen-1-ol > 4-amino-3-hydroxynaphthalene-1sulphonic acid > naphthalene-1,5-diol. This indicates the higher solvation of the ligands in the order naphthalen1-ol > 4-amino-3-hydroxynaphthalene-1-sulphonic acid > naphthalene-1,5-diol.

The linear functions ((22) and (25)) (Figures 4 and 5) used for the calculation of the enthalpy and entropy values imply that such parameters do not vary largely within the (large) temperature range explored (293.15-213.15 K); that is, the heat capacity change of the system is basically small.

\section{Conclusions}

The acid-base properties and the solubilities of naphthalen1-ol, naphthalene-1,5-diol, and 4-amino-3-hydroxynaphthalene-1-sulphonic acid were determined in pure water and in different concentrations $\left(0-4 \mathrm{~mol} \mathrm{~kg}^{-1}\right)$ of aqueous $\mathrm{KCl}$ 
solutions at the temperature range of $T=(293.15$ to 213.15$) \mathrm{K}$ at $5 \mathrm{~K}$ intervals. The values of the total solubilities $\left(S^{\mathrm{T}}\right)$ for naphthalen-1-ol and naphthalene-1,5-diol were found equal to that of their neutral species $\left(S^{0}\right)$. On the other hand, the total solubility for 4-amino-3-hydroxynaphthalene-1sulphonic acid is different from that of its neutral species. The solvation processes of all studied ligands are nonspontaneous and endothermic processes. The solvation of the ligands has the order naphthalen-1-ol > 4-amino-3-hydroxynaphthalene1-sulphonic acid > naphthalene-1,5-diol. The protonation processes of all studied ligands are spontaneous and exothermic processes.

\section{Conflict of Interests}

The author declares that there is no conflict of interests regarding the publication of this paper.

\section{References}

[1] P. Boffetta, N. Jourenkova, and P. Gustavsson, "Cancer risk from occupational and environmental exposure to polycyclic aromatic hydrocarbons," Cancer Causes and Control, vol. 8, no. 3, pp. 444-472, 1997.

[2] M. D. Gammon and R. M. Santella, "PAH, genetic susceptibility and breast cancer risk: an update from the Long Island Breast Cancer study project," European Journal of Cancer, vol. 44, no. 5, pp. 636-640, 2008.

[3] B. Armstrong, E. Hutchinson, J. Unwin, and T. Fletcher, "Lung cancer risk after exposure to polycyclic aromatic hydrocarbons: a review and meta-analysis," Environmental Health Perspectives, vol. 112, no. 9, pp. 970-978, 2004.

[4] A. C. Olsson, J. Fevotte, T. Fletcher et al., "Occupational exposure to polycyclic aromatic hydrocarbons and lung cancer risk: a multicenter study in Europe," Occupational and Environmental Medicine, vol. 67, no. 2, pp. 98-103, 2010.

[5] J. D. Meeker, L. Ryan, D. B. Barr, and R. Hauser, "Exposure to nonpersistent insecticides and male reproductive hormones," Epidemiology, vol. 17, no. 1, pp. 61-68, 2006.

[6] J. D. Meeker, D. B. Barr, B. Serdar, S. M. Rappaport, and R. Hauser, "Utility of urinary 1-naphthol and 2-naphthol levels to assess environmental carbaryl and naphthalene exposure in an epidemiology study," Journal of Exposure Science and Environmental Epidemiology, vol. 17, no. 4, pp. 314-320, 2007.

[7] J. A. Kiernan, Histological and Histochemical Methods: Theory and Practice, Cold Spring Harbor Laboratory Press, 4th edition, 2002.

[8] C. Bretti, A. Giacalone, A. Gianguzza, D. Milea, and S. Sammartano, "Modeling S-carboxymethyl-1-cysteine protonation and activity coefficients in sodium and tetramethylammonium chloride aqueous solutions by SIT and Pitzer equations," Fluid Phase Equilibria, vol. 252, no. 1-2, pp. 119-129, 2007.

[9] C. Bretti, C. De Stefano, G. Manfredi, and S. Sammartano, "Solubility, activity coefficients and acid-base properties of three naphthol derivatives in $\mathrm{NaCl}(\mathrm{aq})$ at different ionic strengths and at T $=298.15 \mathrm{~K}$," Journal of Molecular Liquids, vol. 158, pp. 50-56, 2011.

[10] H. M. Irving and H. S. Rossotti, "The calculation of formation curves of metal complexes from $\mathrm{pH}$ titration curves in mixed solvents," Journal of the Chemical Society, pp. 2904-2910, 1954.
[11] H. Irving and H. S. Rossotti, "Methods for computing successive stability constants from experimental formation curves," Journal of the Chemical Society, pp. 3397-3405, 1953.

[12] C. De Stefano, P. Princi, C. Rigano, and S. Sammartano, "Computer analysis of equilibrium data in solution. ESAB2M: an improved version of the ESAB program," Annali di Chimica, vol. 77, pp. 643-675, 1987.

[13] L. Pettit and K. J. Powell, “The IUPAC stability constants data base," Academic Software, 2001.

[14] F. Crea, A. De Robertis, and S. Sammartano, "Medium and alkyl chain effects on the protonation of dicarboxylates in $\mathrm{NaCl}_{(\mathrm{aq})}$ and $\mathrm{Et}_{4} \mathrm{NI}_{(\mathrm{aq})}$ at $25^{\circ} \mathrm{C}$," Journal of Solution Chemistry, vol. 33, no. 5, pp. 499-528, 2004.

[15] C. Bretti, C. De Stefano, G. Lando, and S. Sammartano, "Activity coefficients, acid-base properties and weak $\mathrm{Na}^{+}$ion pair formation of some resorcinol derivatives," Fluid Phase Equilibria, vol. 292, no. 1-2, pp. 71-79, 2010.

[16] C. Bretti, C. De Stefano, F. J. Millero, and S. Sammartano, "Modeling of protonation constants of linear aliphatic dicarboxylates containing -S-groups in aqueous chloride salt solutions, at different ionic strengths, using the SIT and pitzer equations and empirical relationships," Journal of Solution Chemistry, vol. 37, no. 6, pp. 763-784, 2008.

[17] P. Crea, A. De Robertis, C. De Stefano, D. Milea, and S. Sammartano, "Modeling the dependence on medium and ionic strength of glutathione acid-base behavior in $\mathrm{LiCl}_{\mathrm{aq}}, \mathrm{NaCl}_{\mathrm{aq}}$, $\mathrm{KCl}_{\mathrm{aq}}, \mathrm{RbCl}_{\mathrm{aq}}, \mathrm{CsCl}_{\mathrm{aq}},\left(\mathrm{CH}_{3}\right)_{4} \mathrm{NCl}_{\mathrm{aq}}$, and $\left(\mathrm{C}_{2} \mathrm{H}_{5}\right)_{4} \mathrm{NI}_{\mathrm{aq}}$, Journal of Chemical \& Engineering Dat, vol. 52, no. 3, pp. 1028-1036, 2007.

[18] F. Gharib, K. Zare, A. Taghvamanesh, and M. Monajjemi, "Ionic strength dependence of formation constants: complexation of $\mathrm{Mo}$ (VI) with aspartic acid," Journal of Chemical and Engineering Data, vol. 46, no. 5, pp. 1140-1144, 2001.

[19] C. Bazzicalupi, A. Bencini, A. Bianchi et al., "Synthesis and coordination properties of highly preorganised polyamine macrocycles," Journal of Heterocyclic Chemistry, vol. 38, no. 6, pp. 1273-1279, 2001.

[20] F. A. Long and W. F. McDevit, "Activity coefficients of nonelectrolyte solutes in aqueous salt solutions," Chemical Reviews, vol. 51, no. 1, pp. 119-169, 1952.

[21] J. Z. Setschenow, "Über die Konstitution der Salzlösungen auf Grund ihres Verhaltens zu Kohlensäure," Zeitschrift für Physikalische Chemie, vol. 4, pp. 117-125, 1889.

[22] C. Bretti, R. M. Cigala, F. Crea, C. Foti, and S. Sammartano, "Solubility and activity coefficients of adipic and pimelic acids in $\mathrm{NaCl}(\mathrm{aq}),\left(\mathrm{CH}_{3}\right)_{4} \mathrm{NCl}(\mathrm{aq})$ and $\left(\mathrm{C}_{2} \mathrm{H}_{5}\right)_{4} \mathrm{NI}(\mathrm{aq})$ at different ionic strengths and at $t=25^{\circ} \mathrm{C}$," Fluid Phase Equilibria, vol. 263, no. 1, pp. 43-54, 2008.

[23] B. Das Bhattacharyya and R. Ghosh, "Salting studies of 1- and 2-naphthols and their thermodynamic quantities of transfer from water to salt solutions at different temperatures," Journal of Chemical and Engineering Data, vol. 31, no. 1, pp. 35-37, 1986.

[24] P. Perez-Tejeda, A. Maestre, P. Delgado-Cobos, and J. Burgess, "Single-ion Setschenow coefficients for several hydrophobic non-electrolytes in aqueous electrolyte solutions," Canadian Journal of Chemistry, vol. 68, no. 2, pp. 243-246, 1990.

[25] G. H. Nacollas, Interactions in Electrolyte Solutions, Elsevier, Amsterdam, The Netherlands, 1966.

[26] T. Hashitami and R. Tamamushi, "Setschenow," in Thermodynamic of Electrolyte Solutions, K. Sosetsu, Ed., chapter 5, The Chemical Society of Japan, 11th edition, 1976. 

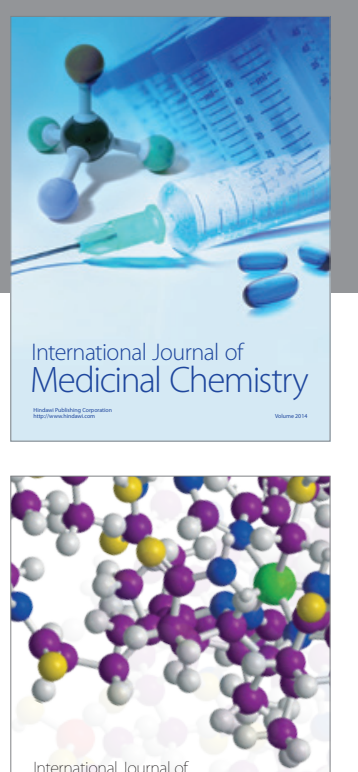

Carbohydrate Chemistry

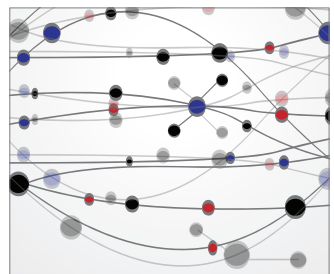

The Scientific World Journal
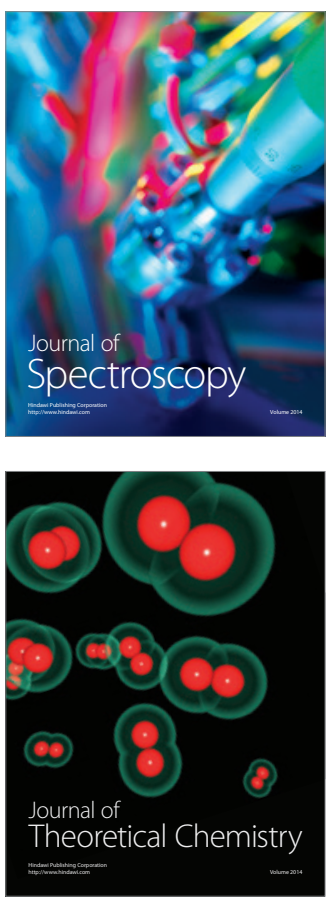
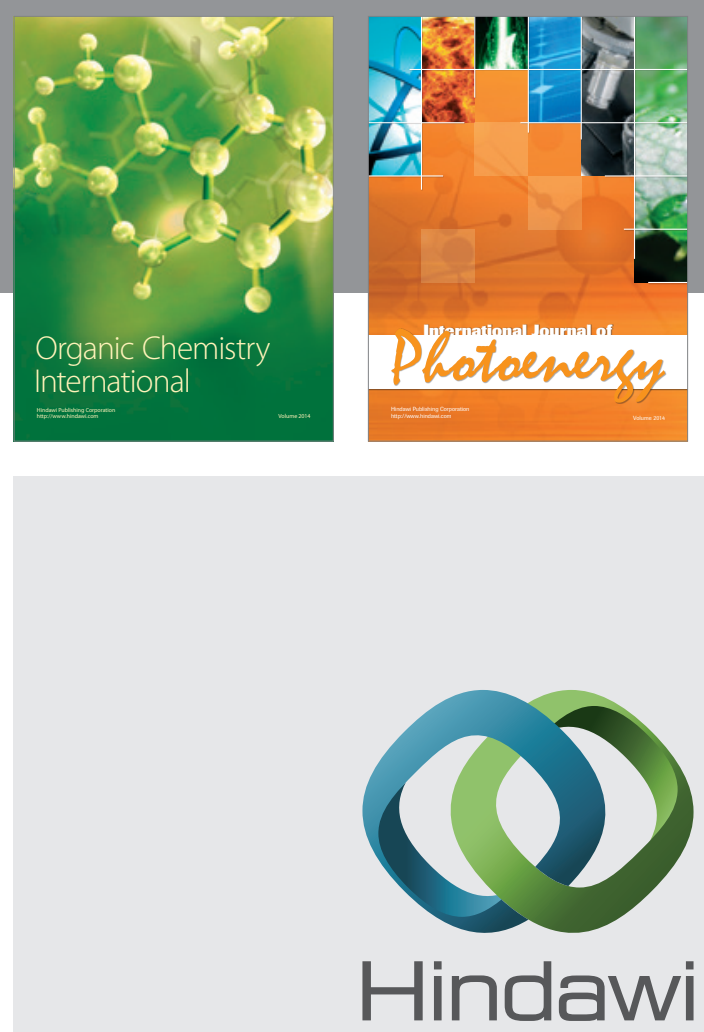

Submit your manuscripts at

http://www.hindawi.com

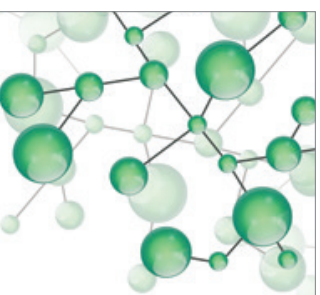

International Journal of

Inorganic Chemistry

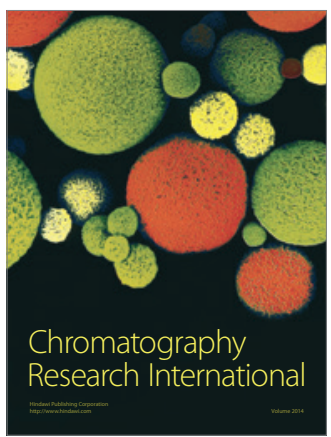

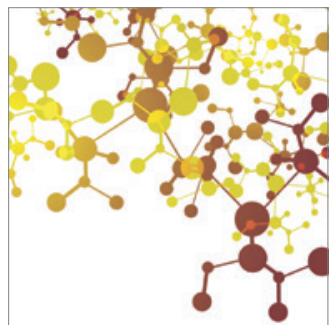

Applied Chemistry
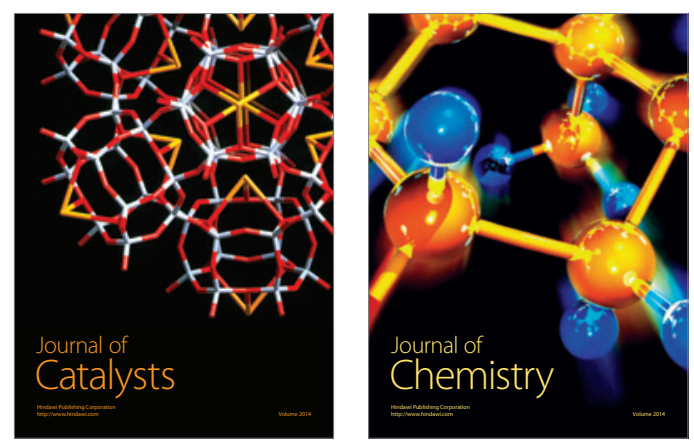
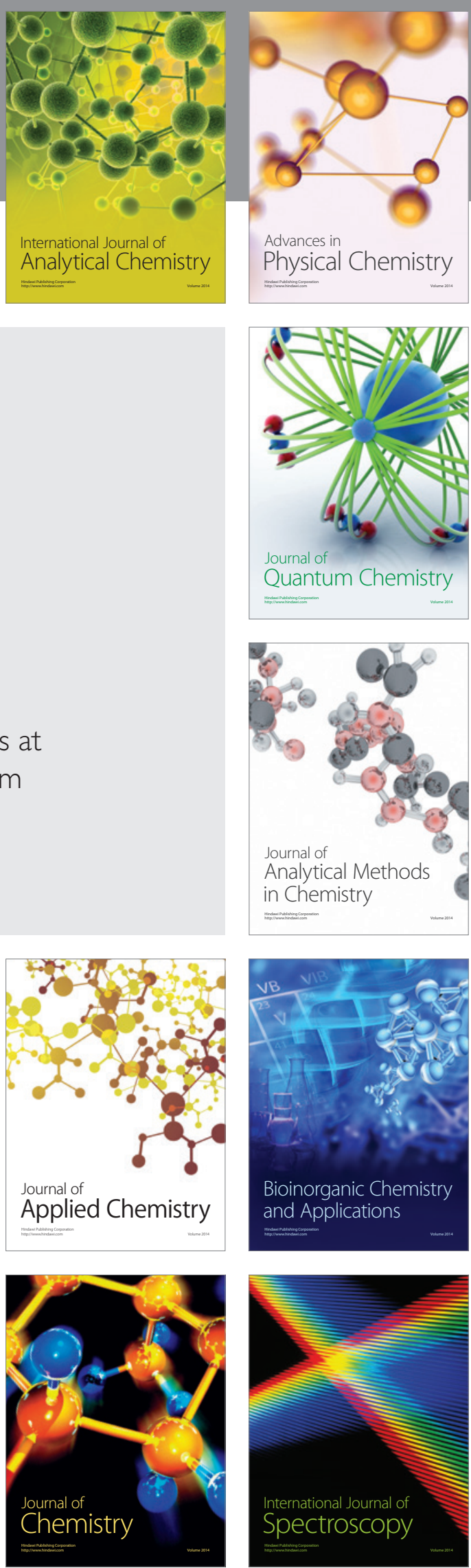